Alejandro Vergara Blanco*

\title{
Naturaleza jurídica del subsuelo y potestades de la administración para disponer su utilización
}

\section{Introducción}

Se ofrece un análisis jurídico relativo al régimen juridico de uso del subsuelo urbano, $y$ de las hipótesis legítimas de indemnización a sus titulares, ante la disposición de su uso por la Adminiscración, como es el caso de la construcción de una obra pública de infraestructura que comprendc una autopista, la que se construye en y ocupa el subsuelo.

Bajo estos supuestos, este análisis scrvirá para responder, por ejemplo, si corresponde pagar una indemnización de perjuicios al titular de una propicdad raiz o de una concesión minera por $\mathrm{el}$ hecho de que en el subsuelo de los terrenos abarcados por su propiedad o su concesión minera, se construirá un túnel. Dados los mismos antecedentes, y bajo el supuesto de que deben ser indemnizadas al propietario del suelo las ocupaciones de tertenos superficiales en los que se construyc una carretera, $y$ aun en los terrenos anexos y cercanos a las bocas de un rúnel, cabe preguncarse: țabe indemnizar al propietario de un predio superficial en cuyo subsuelo, y con una gran profundidad (por ejemplo, supcrior a 100, 200 ó 300 metros), se construirá un túnel?

Para ello, desarrollo un esquema sucinto sobre la naturaleza jurídica del subsuelo.

Profesor sitular de Derector Administrativo Pontificia Univeridad Cutolica de Chite

\section{Extensión horizontal y vertical de la propiedad}

En el plano horizoncal la extensión espacial de los inmuebles queda detcrminada por los linderos o deslindes del mismo. En caso de que no existieran, o no estuvieren fijados, el Código Civil establece el procedimiento para la demarcación. En el plano vertical 
se presenta el problema tanto para determinar la extensión del espacio sideral como la extensión que le corresponde al propietario del subsuelo.

En el plano vertical, nos enfrentamos al "vuelo" (cielo) y al subsuelo. Nos interesa el subsuelo.

En Chile no existe norma expresa que confiera al propietario del suelo superficial el dominio sobre el subsuelo. Para parte de la doctrina (Pescio, Figueroa Valdés) en nuestro país cabe aplicar la tesis romana clásica, dado que algunos artículos dispersos en el ordenamiento jurídico civil, tales como el $879,931,942$ y 945 , darían a entender que el propietario superficial to es también del subsuejo. En este sentido, Claro Solar estima que "la propiedad del suelo abarca en toda su extensión (...), todo lo que se balle sobre el suelo o debajo del suelo. A su juicio, son "elementos constitutivos del suelo mismo".

\section{Referencia a algunas legislaciones extranjeras}

A diferencia de la legislación civil chilena, el Código Civil francés y el Código Civil español establecen expresamente que el dueño del suelo también lo es del subsueto. Ambos códigos no limitan el derecho de dominio que se tendría sobre el subsuelo (sin perjuicio de las limitaciones que el Código Civil Español prescribe en favor de normas de Policia y otras). No obsrante, tanto la doctrina como la jurisprudencia españolas y francesas, están contestes en considerar que sólo se extiende el derecho de dominio sobre la superficie o sobre el suelo hasta el límite donde le sea útil al propietario².

A su vez, existen diversas codificaciones que han regulado expresamente la extensión vertical de la propiedad.

Así:

a) El Código Suizo en su artículo 767 declara que la propiedad del suelo comprende la superficie y el subsuelo en toda la altura y la profundidad útiles a su ejercicio ${ }^{3}$;

b) En el mismo sentido, el Código Civil peruano de 1984 en su artículo 854 dispone que la propiedad del predio se extiende al subsuelo y al sobresuelo dentro de los planos verticales del perímetro superficial, $y$ hasta donde sea útil al propietario el ejercicio de su derecho,

c) Por su parte, el artículo 840 inciso $2^{\circ}$ del Código Civil Italiano establece que el propietario del suelo no puede oponerse a la actividad de terceros que se

Clako SOLAR Luis (1930).

Alessandra Rodríguez, Arturo, y Somararva Undurraga, Manuel Curso de Derecho Civil, Tomo ll De los sujetos y y de los abjetos dej Derecho, Editorial Juridica Nascimento. Santiago 1940.

ALEssandri y Somarkrya (1940). 
desarrollan a tal profundidad en el subsuelo o a ral altura en el espacio superpuesto, que no pueda tener interés en impedirlá;

d) Siguiendo la misma orientación, el Código Civil Alemán indica en su artículo 905 que el derecho del propietario de una finca se extiende al espacio sobre la superficie y al cuerpo de tierra bajo la superficie. El propietario no puede prohibir interferencias que se realicen a tal altura o profundidad que él nо tenga ningún interés en la exclusión.

\section{El subsuelo en la historia jurídica}

a) Época medieval. Una extendida fórmula atribuida modernamente a un glosador (Cino de Pistoya), según la cual "cuitus est solum eitusest usque ad coelum [sidera], usque ad inferos [profundum]", significando que la propiedad det suelo se extiende hasta el cielo y el infierno, ha contribuido grandemente a la exageración del alcance del concepto de "propiedad" del suelo consagrado en el detecho romano clásico; $y$, como consecuencia de ello, a la creencia general de que en esta época no exiscieron, de ningún modo, derechos de explotación de las minas, diferentes y separados de la propiedad del suelo, la que se extendía "ad inferos".

b) El Code Civil francés de 1804. Es ineludible mencionar el Code Civilde 1804, cuyo artículo 552 inciso $1^{\circ}$ dispone que "la propiedad del suelo comprende la propiedad de la parte superior [superficie] ("dessus") y del [fondo] ("dessous")" Nótese cómo el codificador francés deriva del concepto de suelo (" $s o l$ ), superficie y fondo; y no utiliza el concepto subsuelo ("tréfonds") como opuesto al suelo ("sols). Ello es explicable, pues la separación bifronte "suelo/subsuelo" no constituye a la época una paridad de la cual se originasen consecuencias jurídicas para los propietarios.

Existía en tal época una óptica plana, de confines horizontales para la propiedad, $y$ la utilización de los materiales subterráneos se concebía de acuerdo al interés y posibilidades técnicas ${ }^{7}$. No se concebía aún una conciencia de ser propietarios hasta lo más profundo de la tierra; idea ésta que será posterior,

$4 \quad$ Pescro V., Victorio Manual de Derecho Civil, Editarial Juridica de Chile, Segunda Edición, 1958.

- Esta máxima o brocardo del awsque ad coelum / ussque ad inferos*, no tiene un fundamento real en el derecho romano, y fue adoprada por juristas del siglo XIX, para graficar la pretendida absolutez y excensión del objeto de la propiedad moderna, e invocindo como garantía una ficticia legitimidad histórica: vid. 'I' evella Sillasi Chiaka, $I$ "limits terticalli" della proprietá fondiaria (Milán, Giuffré, 1994) $\mathrm{p}$. 140 . Fsta fortada adaptación ancihistórica del derecho romano de propiedad al arquetipo de la propiedad moderna, es. además, una explicación a orro exccso decimonónico, que aún perdura en las fuentes del derecho chileno: la atribución legal de la propiedad da las minas *al Fstado*, curtu úanica Kórmula de romper esta hipérbole que le arribuve al dueño del suejo la propiedad de todo el subsuelo, incluidas las minas. Véase VerGars (2006): La naturaleza juridica de la riqueza mincral.

Texco en francés del art. 552 inc. $1^{\circ}$ : «a propriete du sol emporte la proprieté du dessuj el du dessousy. Cir.: Ten.filla Snilani (1994) p. 626. 
originada en ideas decimonónicas, tendentes a apoyar una concepción absoluta de la propiedad, ideas individualistas estas que traerán por reacción defensiva una nueva patrimonialización de los minerales, ahora ya no por parte de los reyes (que eran parte del pasado) sino del nuevo titular del poder social: del Estado.

Será la doctrina sucesiva a la dictación del Código Civil francés, del siglo XIX y aun del XX, en especial la llamada Escuela de la Exégesis, la que seguirá insistiendo en una idea estática, vertical, de una propiedad individual y excluyente del subsuejo, apoyándose para ello en el tenor literal de este artículo 552 (aunque, como decimos arriba, de su tenor literal no se deriva una bipartición dogmática suelo(subsuelo), desempolvando además de los antiguos textos medievales el brocardo cuius est solum eius est usque ad coelum, a la que le adjuntaron la expresión usque ad inferos, trayéndola transformada, de la fórmula usque ad profundum que los juristas habían conocido para tutelar los intereses de los propietarios del suelo al disfrute del subsuelo para defenderse de la regalía soberana. Tesis esta que, incluso, apoyaron artificialmente en antecedentes romanos, lo que tambiến era irreal ${ }^{8}$.

Ya veremos que esto producirá la permanente tensión entre propiedad del suelo y explotación de las minas por terceros, y la decisión legislativa decimonónica de los Estados nacionales de recuperar la antigua regalía minera, con contenido patrimonial, con el fin de evitar que los propietarios del suelo, aplicando esta hipérbole, se considerasen dueños del suelo y del subsuelo. Un exceso (considerar a los propietarios como dueños del subsuelo "hasta el infierno", "hasta lo más profundon) traerá como consecuencia otro exceso (considerar por la vía legislativa, al Estado, como "dueño" de las minas). Pero para esto último será necesario traspasar un problema «técnico-jurídicon: la necesidad de transformar al «Estado" en sujeto del derecho de propiedad; ello origina la urilización de otra institución de derecho privado: la personalidad jurídica o moral, y se recurrirá a la artificiosa teoría de la personalidad jurídica del Estado; mito este último que aún pervive en gran parte de la doctrina; mito éste que, por lo demás, será muy útil para la elaboración del art. 591 del Código Civil chileno, de 1857,y posteriormente del art. $19 \mathrm{~N}^{\circ} 24$ inc. $6^{\circ} \mathrm{CP}$ de 1980 , por mencionar los dos extremos históricos patrios en la materia. Sólo con el mito de la personalidad juridica del Ėstado es coherente esa atribución de un "derecho de propiedad" al Estado... sobre el subsuelo.

El inciso $3^{\circ}$ del art. 552 del Code conlleva sin embargo una restricción importante al ius fodiendi: señala que si bien el propietario puede hacer "debajo" ("dessousi) construcciones y extracciones, ello es "salvo las modificaciones resul-

4. Vid. la que decimos infra n. 12. 
tantes de las leyes y reglamentos relativas a las minas", referencia evidente a las limitaciones vigentes de las normas especiales contenidas en la ley de 1791 .

c) Ley francesa de Minas de 1810. Como se ha dicho, ya se había infiltrado como idea común, a partir del Code Civil, sostener que el propietario de la superficie era al mismo tiempo, por la vía de la accesión, propietario del subsuelo, no solo en la medida necesaria para realizar todos los actos usuales de propiedad en el suelo, sino también en el subsuelo mineral. Por ello, esta será una ley práctica, reflejando tales ideas individualistas como también los necesarios cambios de ideas acerca de la función económica de las minas, con tal de hacerlas producir. El "Estado" se transforma en guardián de los intereses colectivos: crea la "propiedad minera" expropiando ał propietario del suelo (y del subsuelo). El sentimiento de que la expropiación constituia el nudo de la ley no sólo estuvo en sus redactores; ha sido la interpretación más recurrida por la doctrina posterior ${ }^{9}$, pero Napolébn tuvo la sagacidad de no asignarlas a la Nación o al "Estado»: las minas no serían ni del propietario del suelo ni de nadie: res nullius.

La Ley de Minas de 21 de abril de 1810 transformó no sólo el derecho minero francés, sino que constituye la base del derecho minero moderno y es evidente su influencia en los textos codificados chitenos del siglo XIX.

El art. $19^{\circ}$ subraya que "cuando una mina es concedida, aun al propietario de la superficie, esta propiedad será distinguida de la superficie y considerada en adelante como una nueva propiedad, sobre la cual nuevas hipotecas podrán otorgarse". Por eso, queda claro que la mina concedida pertenece a su explotante, como "propiedad minera".

Conforme a las ideas del propio Napoleón, es la expropiación la que justifica la creación de la propiedad minera, pues las minas tienen una utilidad social. El que posee los recursos y la capacidad debe explotar las minas y, por ende, debe tener su propiedad, en desmedro del propietario del suelo, que se encuentra entonces expropiado de la propiedad del subsuelo que le prometía el Code Civillo.

\section{Doctrina moderna del interés en relación al subsuelo}

Cabe siquiera esbozar la doctrina llamada "del interés", cuyo planteamiento es atribuido a Ihering, y que se sigue en varias codificaciones modernas como la brasilera, la alemana, la suiza e italiana antes mencionada.

Cfr., por todos: PLAvioz (Igo6) p. $764 n^{\circ} 2394$, para quien usi bien ta letra del Código [art. 552] ha sido resperada. su espiritu ha sido desconocido», pues a su juicio la ley de 1810 io que opera es una verdadera *exproppiacićctur a lus propietarios del suelo (y del subsuelo).

10 Ver un mejor desarrollo cn: VERGaRA 2007: instimeciones de derecho de mineria (en preparación). 
La referida doctrina es una postura intermedia entre el postulado del Derecho Romano afinado por los postglosadores ("por arriba hasta el cielo, por abajo basta el infierno"), que buscaba principalmente defender a los terratenientes de la pretensión de los señores feudales a disfrutar de las riquezas mineras y que se quería incluir dentro de las regalías" y la teoría restrictiva, que reduce la propiedad sobre un inmueble a la superficie del suelo, entregando al Estado la disposición del espacio sideral y del subsuelo.

El criterio doctrinario del interés consiste, para algunos, en limitar el derecho de propiedad, mientras que para otros, se traduce en la imposibilidad de oponerse a las inmisiones de terceros que no perturban al propietario, afectando en este último caso al ejercicio del derecho de propiedad.

Ya sea que se acoja la explicación de la limitación del derecho de propiedad o de la ejercitabilidad del mismo, la restricción al propietario del suelo superficial quedaría materializada positivamente en el interés práctico y razonable del propietario del predio superficial para ocupar el subsuelo y negativamente, en cuanto a la imposibilidad de dicho propietario superficial de oponerse a la actividad de terceros que se desarrolle a gran profundidad en el subsuelo por la carencia de perjuicios que dicha actividad le reporte.

La doctrina del interés ha llevado a que la doctrina y la jurisprudencia comparada estimen que la propiedad verticalmente no es absoluta y que el propietario del inmueble extiende su derecho al espacio que cubre el inmueble y al subsuelo, en la medida en que el interés, el provecho y la utilidad del ejercicio de su dominio lo justifique, no pudiendo oponerse a inmisiones de terceros (como aeronaves o excavaciones profundas en el subsuelo) que no afecten su dominio al no producirle perjuicios.

\section{Legislación chilena y "subsuelo"12}

En la legislación chilena, en cuanto al subsuelo, no hay disposición expresa que lo atribuya al propietario; el artículo 942 , por ejemplo, lo da por supuesto; por lo demás resulta indiscurible, at menos en alguna medida, si se piensa que para poder ejercitar el dominio necesita siempre el propietario usa la parte inmediatamente inferior a la superficie (para cultivos, cimientos de construcción, etc.) ${ }^{15}$. De esta manera ni la doctrina ni la jurisprudencia han tomado un sendero claro en la materia, y no han atribuido el dominio del subsuelo ilimitadamente ni al propietario superficial ni al Estado, y sólo se

\footnotetext{
La Rocca Maitar, Paola: Propiedad del Subsuelo Utbano (Falitorial Juridica La Ley, Sanuiago, 1995), p. 185.

Víasc sobre el tema: Fitgufrox Velasco, Patricio y Figueron VALdés, Juan (2006): "Utbanismo y Canutracción" (Samtiago, LexisiNexis) 327 pp. [E] "subsurlo utbano", pp. 85 y 86); Fisuf.ron VaLdés, Juan (2000]: "Régimen tegal del substelo urbane" Revista de Detecho y Jurispredencia, tomo XCVII, No 3, I, Pp. 121-128, GILIMORF. LavDon, Roberto Seminario Santiggo Sub-Tetra: Desafios y Oportundades. Centro de Investigaciones Temritoriales y UrbanasCITU. Facultad di Arquirectura y Diseño UNAB. Cámara Chilcna de la Construcción: ", LA Ruccit MatTar (1995): Propiedad del subsuelo urbano de los bienes nacionales de nuo puiblico y fucales (Santiago, Edicorial Jurídica La Lcy).

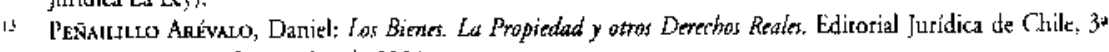
F.dición, Sanniago, Septicmbre de 2004.
} 
han pronunciado con respecto a los minerales existentes en el mismo, atribuyéndolos al dominio del Estado de acuerdo a la concepción del dominio eminente.

Sin embargo, algunos autores chilenos se han pronunciado a favor de la teoría de la utilidad o del interés, entre ellos destacan Alessandri, Somarriva y Vodanovic que exponen: "como ninguna disposición legal seńala el límite del derecho del propietario, podemos decir, de acuerdo con la teoŕa moderna, que el suelo pertenece al dueño del suelo hasta la profundidad requerida por el interés que determina el uso del inmueble ${ }^{m ! s}$.

En consecuencia, se podría decir que la tesis del interés no está tratada orgánicamente en ningún texto legal, y tanto la doctrina como la jurisprudencia, aparte de ser escasa, no se ha pronunciado uniformemente sobre el tema (la gran mayoría se refiere a la teoría del interés como un criterio moderno de la legisiación y de la doctrina comparada), pero que a su vez, no ha sido despreciada por esta última y tampoco existe disposición legal alguna que impida su inserción doctrinaria. En otras palabras, la doctrina en Chile no argumenta directa y enfáticamente por la doctrina de interés.

\section{El propietario es tal sólo respecto del suelo utilizable material y jurídicamente}

Nuestro ordenamiento jurídico, en especial la Constitución Política de la República, ha dado una especial protección a la propiedad privada y a su ticular, al disponer en el inciso $3^{\circ}$, primera parte, del artículo 19 número 24 , que:

"Nadie puede, en caso alguno, ser privado de su propiedad, del bien sobre que recae o de alguno de los atributos o facultades esenciales del dominio, sino en virtud de ley general o especial que autorice la expropiación por causa de utilidad pública o de interés general, calificada por el legislador".

De esta manera, se impide que un particular sea despojado de parte de su propiedad privada sin que se le expropie por las causas indicadas.

Por lo anterior, es necesario determinar el objeto que constituye el bien sobre el cual recae el derecho de dominio del propietario superficial. Para ello cabe trazar los limites de dicho objeto utilizando criterios objetivos y aplicables a la generalidad de los casos.

En este sentido, La Rocca Mattar ${ }^{15}$ enuncia y analiza algunos de los referidos criterios, señala que una primera delimitación estaría dada por cuanto el interés del propietario superficial debe tener carácter económico, es decir, debe referirse a la urilización que el propietario superficial quiera y pueda darle al subsuelo bajo su propiedad, teniendo en cuenta los avances de la técnica y de la arquitectura.

14 Alessandri Rodrícuez, Arturo, Somerrriva Undurraga. Manuel y Vodanovic, Antonio. "Tratado de los Derechos Reales" Los Bienes. Tom, I, Sexta Edición, Editorial Juridica de Chile, Santiago, 1997.

1: La Rocca Martar, Paola: Propiedad del Suelo Urbano, Edirorial Jurídica La Ley, Santiago, 1995. 
Pero el criterio anterior no es suficiente para limitar la extensión del dominio sobre el subsuelo, ya que la casuística puede ser infinita; necesariamente el interés económico del propietario sobre el subsuelo debe tener un matiz objetivo o aplicable a una generalidad de situaciones, es decir, debe referirse a cualquier aprovechamiento posible objetiva $y$ abstractamente considerado. De esta manera, el carácter objerivo opera en función de un interés económico-social y no en función del arbitrio de cada propietario superficial.

Asimismo, es necesario determinar si dicho incerés económico-social, objetivo y abstracto, que debe tener el propietario superficial, requiere ser el actual o el que eventualmente pueda adquirir. En este sentido, se ha sostenido que el aprovechamiento económico-social, objetivo y abstracto del titular del predio superficial debe ser actual, entendiéndose que dicha actualidad no está condicionada al aprovechamiento que se tiene al momento en que se produce la inmisión de terceros en el subsuelo, sino que dice relación con la posibilidad de aprovechamiento cuya realización pueda obtenerse en un tiempo previsible y de acuerdo con la evolución normal de las cosas y la experiencia de la técnica y el arte, combinando beneficiosamente la delimitación de los derechos del propietario superficial con la futura ampliación de sus intereses.

\section{Aplicación al caso de la construcción de una obra pública consistente en una carretera subterránea (túnel)}

En atención a la fundamentación explicitada anteriormente, cabe determinar la necesidad de expropiar o no el subsuelo de los propietarios superficiales en el espacio en que se construirá el túnel en virtud de la concesión de obra pública para construir una autopista consistente en un túnel.

Se puede concluir que en la parte del subsuelo donde no existe interés del propietario superficial no existe propiedad privada o al menos facultad de excluir inmisiones de terceros. En razón de dicho postulado, si no hay propiedad privada, no existe objeto que expropiar. Lo anterior faculta a quien está en posesión de un título concesional de obra pública para poder llevar a cabo la construcción de la obra concesionada en el espacio de subsuelo concesionado sin la necesidad de contar con una ley general o especial expropiatoria ya que la inmisión en el subsuelo se materializaría en bienes sobre los cuales la Administración puede ejercer una potestad administrativa y que puede ser otorgado su uso por la vía de una concesión de obra pública (dentro de la competencia otorgada en virtud del artículo 39 inciso $3^{\circ}$ de la Ley de Concesiones de Obras Públicas ${ }^{16}$ ).

En efecto, dicha disposición legal no deja lugar a dudas que:

"En las obras que se otorguen en concesión en virtud de esta ley se podrá incluir, conjunta o separadamente, la concesión del uso del subsuelo $(\ldots)$ ".

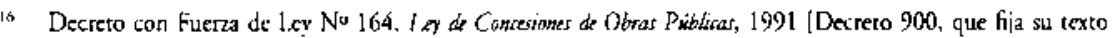
refundido, coordinado y sistematizado, 1996. 
Lo anterior sin perjuicio que, además (pues la ley distingue claramente), se puede otorgar "derechos de construcción en el espacio".

En otras palabras, el tículo jurídico de una concesionaria para usar el subsuelo de una propiedad privada es la concesión de obras públicas.

A mayor abundamiento, reafirma el hecho de que no se requiere expropiar el subsuelo sobre el cual se emplaza la propiedad superficial bajo la cual se desarrollarán las obras públicas, el hecho de que con la construcción del túnel no se causará perjuicio o menoscabo alguno a la propiedad del propietario superficial y una condición sine qua non para que exista expropiación es que debe indemnizarse el daño efectivamente producido. En el caso en cuestión no existe perjuicio alguno, por tanto no hay daño al propietario superficial que indemnizar y por ello no procede expropiar.

\section{Conclusiones}

$1^{\circ}$ En Chile no existe disposición legal alguna que arribuya al propietario superficial el dominio del subsuelo existente bajo su propiedad. Para parte de la docrrina por aplicación de algunas normas dispersas en el Código Civil (como lo seria el artículo 942), se entiende que se le atribuiría su dominio al propietario superficial. Algunas codificaciones extranjeras, expresamente establecen que la propiedad vertical está limitada por el interés práctico que el titular del predio superficial pueda obtener, desarrollando asi la teoría del interés que se traduce en la imposibilidad de oponerse a inmisiones de terceros que no perturban al propietario o en una limitación a la extensión vertical de la propiedad.

$2^{\circ}$ Nuestro ordenamiento jurídico brinda especial protección a la propiedad privada. Por ello, para poder dar cabida a la doctrina del interés, debe delimitarse necesariamente el objeto sobre el cual recaería el dominio del propietario superficial en el provecho del subsuelo con un criterio de interés socio-económico, abstracto, objetivo y actual, entendiendo que dicha actualidad debe coordinarse con la futura ampliación de los intereses del propietario superficial.

$3^{\circ}$ En cuanto a la figura de expropiar el subsuelo, aplicando la teoria del interés, ello no tendría lugar, debido a que al no haber interés del propietario superficial en la utilización del subsuelo, no habría derecho de propiedad privada sobre el mismo y la expropiación careceria de objeto. Lo anterior, atendida la necesidad de que un requisito de la expropiación es que debe haber una indemnización de perjuicios al afectado y en el presente caso no se produce menoscabo alguno al propietario superficial con la construcción de un túnel que pase a gran profundidad bajo su predio.

$4^{\circ}$ La autoridad administrativa se encuentra facultada para otorgar, conjunta o separadamente, en una concesión de obra pública, el uso del subsuelo de bienes privados y públicos. 
